\title{
Nepalese Health System Response to Fight against COVID-19 Pandemic
}

\author{
Sharada P Wasti ${ }^{1}$ Padam Simkhada ${ }^{2}$, Sudip Ale Magar ${ }^{3}$, Edwin van Teijlingen ${ }^{4}$
}

\author{
Author Info: \\ 'Senior Research Fellow, \\ School of Human and \\ Health Science, University of \\ Huddersfield, UK. \\ ${ }^{2}$ Professor, School of Human \\ and Health Science, University \\ of Huddersfield, UK \\ ${ }^{3}$ Public Health Officer, Ministry \\ of Health and Population, \\ Kathmandu, Nepal \\ ${ }^{4}$ Professor, Centre for \\ Midwifery, Maternal \\ \& Perinatal Health, \\ Bournemouth University, \\ England, UK \\ Corresponding Author: \\ Sharada P Wasti \\ Email: s.p.wasti@hud.ac.uk \\ ORCID ID:https://orcid. \\ org/0000-0001-8833-7801
}

\begin{abstract}
The novel coronavirus or COVID-19 is a new highly infectious virus affecting a large population across the globe. There is no specific therapeutic drug available against COVID-19, hence the most affected public health measures need to strictly be adhered to without delay. A range of issues were reported to fight against COVID-19 in the current health system of Nepal which should be addressed to strengthen the full spectrum of the health system for its effective and sustainable response. It is crucial to understand the current health system at the local, provincial level and sincerely adhere the federal government policies and plan as per the protocol for maintaining minimum infection prevention and control measures with having preventive and safety measures to both service providers and community people. To tackle those daily increasing number of COVID-19 cases, it provides an opportunity for the three tires of governments to reprioritize the health service in the national agenda for the effective prevention and response it. Although national health policy 2019 clearly articulated the need for equitable access and quality of health care services to all. Evidence shows that Nepal is in risk zone because of comparably weak health system that should be aware of all three levels of government in Nepal and strengthen and control the present threat posed the daily increasing cases of pandemic.
\end{abstract}

Keywords: COVID-19, WHO-Building Block, Health System, Nepal

\begin{tabular}{|c|c|c|}
\hline QR Code & \multicolumn{2}{|l|}{ Article Info } \\
\hline$\Delta$ View PDF & Accepted: 26 February 2021; & Published Online: 27 February 2021 \\
\hline 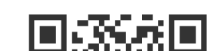 & \multicolumn{2}{|l|}{ How to cite this article in Vancouver Style? } \\
\hline 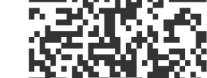 & \multicolumn{2}{|c|}{$\begin{array}{l}\text { Wasti SP, Simkhada P, Magar SA, van Teijlingen E. Neplease Health System Response to Fight against COVID-19 } \\
\text { Pandemic. Europasian J Med Sci. 2021;3(1): 98-104. https://doi.org/10.46405/ejms.v3i1.262 }\end{array}$} \\
\hline & \multicolumn{2}{|l|}{ Disclaimer } \\
\hline & Conflict of Interest: None Declared; & Source of Support: Nil \\
\hline \multicolumn{3}{|c|}{$\begin{array}{l}\text { Copyright (C) } 2021 \text { by author(s). This work is licensed under the terms and condition of Creative Commons Attribution International } \\
\text { License } 4.0 @ \text { (\$) (http://creativecommons.org/licenses/by/4.0/) which permits unrestricted use, distribution, and reproduction in any } \\
\text { medium, provided the original work is properly cited. This is an open access publication, and can be downloaded freely from the } \\
\text { website of the Journal: www.europasianjournals.org. The Journal as well as publisher remain neutral with regards to any jurisdictional } \\
\text { claims in any published articles, its contents and the institutional affiliations of the authors. The Europasian Journal of Medical Sciences } \\
\text { (EJMS) (www.europasianjournals.org) is an official Journal of Nirvana Psychosocial Care Center \& Ressearch Institute (www.nirvanapscc. } \\
\text { com). }\end{array}$} \\
\hline
\end{tabular}




\section{BACKGROUND}

Health systems around the world are being challenged by the increasing demand of care for people with COVID-19 compounded by limitations on movement that disrupt the health service delivery. The first case of COVID-19 was reported from Hubei Province of China in late 2019, and by 10 July 2020, over 12 million confirmed cases with 545,481 deaths were reported from 215 nations. ${ }^{1}$ Current global health systems are overwhelmed, and people fail to access services that lead to increase both in direct mortality from COVID-19 outbreak and indirect mortality from preventable and treatable conditions. COVID-19 was declared a pandemic by the World Health Organization (WHO) in March 11, 2020 and two weeks later the Government of Nepal enforced a lockdown. On 23 January 2020, Nepal officially announced its first confirmed COVID-19 case, who had travelled from China. ${ }^{1}$ The cumulative total cases have increased regularly which is significant concern for the current health system of Nepal. The number of new cases is increasing by more than 100 each day and this crisis places pressure on all health systems of WHO's six building blocks which framework promote a common understanding of what a health system is and area for strengthening. Its conceptualized on service delivery, health workforce, information, medical products and technologies, financing, and leadership and governance of the health system strengthening in Nepal. ${ }^{2}$ In this context, this framework is used to understand the current national health system and area to strengthen to response of COVID-19 pandemic through improving access, coverage, quality and safety. ${ }^{2}$

In the early phases of the COVID-19 outbreak, many health systems including Nepal's were able to maintain routine service delivery in addition to managing a relatively limited COVID-19 caseload. With a pressure on services many routine and elective services have been suspended or adapted to the pandemic. At this stage, effective governance, coordination and protocols for service prioritization and adaptation can mitigate the risk of outright system failure. ${ }^{3}$ The increasing number of new COVID-19 infections has impacted on Nepal's health system's ability to offer preventative measures. This paper aimed to understand those issues and challenges for the effective response of national health system towards COVID-19 in Nepal.

\section{Literature search strategy and synthesis}

Electronic journals, newspaper/media coverage and reports related on the COVID-19 outbreak and health system related materials were accessed by using Google, Google Scholar, Ministry of Health and Population (MoHP) and national daily newspapers of Nepal. Other "grey literature" (especially COVID-19 related documents) published by MoHP and external development agencies publications were also searched. The review synthesized the current literature and presented in the health system framework of WHO six building blocks themes: 1) health system response to COVID-19; 2) procurement systems around medical supply, 3) inconsistent prevention information/messages, 4) health workforce, 5) financing, and 6) leadership and governance of Nepal's health system response on COVID-19 pandemic.2

\section{Health system response to COVID-19}

The Government of Nepal (GoN) has made several decisions related to lockdown, instructed people to stay home except for emergency reason with maintaining social distances and established number of temporary quarantine centres, isolation beds in hospitals and a 24 hours' health desk at the International Airport. The major border districts have also established the health checkpoints and regularly screened those passengers who came from abroad. A high-level technical team was formed to monitor the situation across the hospitals network. Regular communication mechanism has established between Health Emergency Operation Center, Provincial Health Emergency Operation Center and Ministry of Social Development. ${ }^{4}$

With Nepal's lockdown, all air and surface travel was halted that caused a shortage of essential supplies such as food and medicine and made it difficult for people to reach health facilities. It has already stretched health care providers have an important role in providing services to the patients. A number of deaths were reported due to not being able to reach at health facilities as well as patients did not get timely services. ${ }^{5}$ The current prevention efforts such as isolate, test, treat and trace process have many issues and monitoring system has a lot of room for the improvement. ${ }^{6}$ Most of the public health experts, researchers, clinicians and different stakeholders raised concerns about the government's weak preparation and unclear strategies for procuring medical supplies, coverage of prevention efforts, mobilizing resources, access to and coverage of services and management of suspected or confirmed cases. ${ }^{7}$ It is crucial to understand the current healthcare systems where many patients have difficulties reaching health facilities and access the services. The disruptions 
to the health system will likely cause more deaths of persons with other urgent health needs than patients diagnosed with COVID-19 for example there has been an almost 200 percent increase in maternal mortality rate since the lockdown in Nepal. ${ }^{9}$ Those who reached facilities often did not get timely services which resulted in death but in records these were not COVID-19. ${ }^{5}$ Those few examples clearly demonstrate that, the current health system needs to be strengthened to response the current crisis or pandemic ${ }^{10}$ and MoHP needs to ensure healthcare institutions become more accountable to respond any sorts of patient.

Similarly, most of health facilities and health care providers raised concern around the reporting system of COVID diagnosed cases from the laboratory which did not inform health facilities providers immediately after diagnosis which caused panic among providers. ${ }^{2}$ There have been instances when test results were reported positive only after the death or even after the funeral of the COVID-19 patients where a case of a 20-year old man of Surkhet district was declared negative to COVID-19 during quarantine stay test but after returning home he died the very same day. After his death, the test result came back positive for COVID-19. ${ }^{11}$ This clearly shows that without immediate information to concern health staff, there is a high chance of transmission to healthcare providers as well as intimidate family members. Therefore, the reporting systems should be smooth and that should also direct to the concerns health workers that may help to apply the preventive measures.

The aim of the COVID-19 prevention programme is to change individual behaviour of those at risk of infection through the non-pharmaceutical intervention by controlling movement, isolation and quarantine facilities. ${ }^{12}$ Quarantine is one of the oldest and most effective public health intervention for responding to communicable disease outbreaks which was practiced in the fourteenth century in Italy. ${ }^{13}$ The Government of Nepal developed its Quarantine Operation and Management Protocol (2076) and 14 days of quarantine was made mandatory for those who came as international air and surface travelers. ${ }^{14} 15$ However, there was huge criticism about the quarantine and its facilities. A study conducted during COVID-19 about the health facilities and revealed that none of the quarantine centres were constructed as per the minimal standard of the protocol. ${ }^{16}$ The government has not yet managed quarantine facilities nor has it arranged for proper facilities as many did not even have drinking water or clean toilets and many had very congested living arrangement as well as issues reported about sexual abuse and suicides. ${ }^{12}$

${ }^{17}$ It is advisable that the delivery of quality services remains one of the important goals of most health systems.

Similarly, the protocol clearly stated that quarantine should have all essential hygiene and sanitation items ${ }^{14}$ but there is concern on how quarantine centres have been responding to the children, lactating mothers, elderly and person with disability but national protocol clearly indicated that these populations should be special consideration. ${ }^{4}$ The pandemic and lockdown have also given concern about their consequences to the mental health of the population. ${ }^{18}$ Incidents of violence against women (VAW) have also increased worldwide since the lockdowns and the UN Women has declared that VAW as a shadow pandemic. ${ }^{19}$ Similar issues were also reported in Nepal inside the quarantine few reported cased of sexual violence/rape and committed suicides. A daily newspaper reported that every ten minutes, a woman somewhere in Nepal dials the helpline telephone 1145 operated by the National Women Commission either looking to report incidents of abuse or calling to inquire about the support services. ${ }^{20}$ It is not clear how long this COVID-19 pandemic will last and to respond the present and future crisis of national health system at all levels of Government of Nepal needs to strengthen and cater the services with applying the precautionary measures. Although, Nepal Health Policy 2019 has put Universal Health Coverage as the centre stressing the need for equitable access and quality of health care services to all people. ${ }^{21}$ Therefore, it is important to strengthen the full spectrum of healthcare system on tracing, isolation and quarantine mechanism and care of COVID-19 patients to respond the current pandemic.

\section{Procurement systems around medical supply}

Logistic supply for the COVID-19 response is a global issue and Nepal is not an exceptional where special Personal Protective Equipment (PPE) for COVID-19 was not in stock which needs to be imported from the global market which took a long time to arrive. A study in hospital assessment in Nepal shows that the supplies of simple face masks, gloves and hand sanitizers were adequate in the majority of hospitals. ${ }^{16}$ The inability to supply and frequent shortages of medical supplies made 
healthcare providers more panic and putting their lives more at risk of transmitting the viruses..$^{22}$

The GoN has expanded the testing facilities across the provinces but there was frequent shortage of the test kits and PPEs in different facilities. ${ }^{16}$ Some border health checkpoints were also running without fully screening passengers coming from India which was high risk of transmitting to their family members or general public. ${ }^{6}$ It was also reported that many doctors treated patients without proper PPEs..$^{23}$ The procurement of commodities, paid prices and quality of commodities were highly criticized during the COVID-19. Due to lengthy procurement policy, the MoHP has faced difficulty to procure and supply commodities on time. Global scenario clearly shows that governments must act quickly to boost supply, ease export restrictions and put measures into place. ${ }^{24}$ The MoHP eases the current procurement system which should be straight forward during the crisis and disasters period in order to uninterrupted supply of the commodities without compromising quality and collusions.

\section{Inconsistent prevention information/ messages}

Health information is widely considered to have been provided by authorities at all levels in a timely manner. GoN has initiated on disseminating the national decision and guidance in the national media. Regular daily briefing about the situation to media by spoke persons of the MoHP initiated and continued to run a separate website with detailed information on COVID-19. The MoHP has also established hotline service and media monitoring and rumour verification. Many healthcare workers were also trained on quarantine, contact tracing and PPE use, and conducted for medical personnel and hoteliers. Different audio and video messages with various public figures were produced so that the public knows it gets only reliable information. ${ }^{4}$

With the outbreak of the coronavirus, the spread of rumours was high about the origin and circulated the globe with use only N-95 face masks vs. no benefits of using N-95 face mask, individual whole-body spray with using chemical and tunnel sanitation which was practised in different parts of Nepal. A number of public health experts suggested that individual body spray and tunnel sanitization is not a scientific practice that caused different skin and eye diseases. ${ }^{25}$ Several places have been linked with new 'infomedia' there the virus spread very rapidly and, moreover, the public in these place panic because of this misinformation. ${ }^{26}$ Despite of number of initiatives on the prevention and response messages by the MoHP, it was seen that the social media panic travelled faster than the COVID-19 ${ }^{27}$ and its dark side being the source of rapidly spreading misinformation, which increases the worries and stress among the public. These uncertainties and worries generated additional media consumption and further distress. ${ }^{28}$

Despite of health and safety messages regarding COVID-19, some patients did not get treatment because some hospitals shut their gates even for fever patients and health workers were also evaded to treat patients until the conditions become severe. Some ambulances did not take patient to hospital. 929 Many confusions were seen on managing COVID positive dead bodies despite of wearing PPE, mortuary van drivers refused to transport the body at the funeral place. ${ }^{30} \mathrm{~A}$ number of communities were stopped from public funeral rituals and funerals were supervised and controlled by the army. ${ }^{31}$ Despite of having a clear protocol and all the communication messages, health workers in the community did not understand the dynamic of COVID-19 prevention measures. Health care workers often panicked when attending patients and / or did not want to attend them in the first places, such was their limited understanding combined with low confidence. Therefore, the current three tires of government need to identify an effective risk communication strategy and materials that tailor responses to the crisis to the health facility to the community and avoid their panic and confusions.

\section{Health workforce}

The Covid-19 pandemic has alarming implications for health care functioning. It is difficult to ensure that there are enough health care providers to response COVID-19 crisis across Nepal and provide regular health services. It has already stretched health care providers that have an important role in monitoring and delivering support to their patients. There was frequent concerned about the inadequate contact tracing which was because of inadequate human resource to do the tracing. Many local levels could not form a team and mobilise it on time resulting in fewer contacts being tracing. Therefore, the GoN should facilitate and ensure the basic requirements at the health facility, readiness of the service sites and empower the health care providers in a timely manner. ${ }^{4}$

The MoHP had trained many health workers in the 
field of epidemiology, emergency preparedness and response and other public health management areas in the past and this human resource could be immediately mobilized at the beginning of this COVID-19 outbreaks. However, the main reason of not mobilizing staff may be not having the updated trained health worker's database. Federal and provincial governments should regularly update and maintain trained human resource databases to respond better and faster to future emergencies (positive cases 2000-5000) but public health emergency had not declared as per Nepal's Health Sector Emergency Response Plan and the GoN failed to have proactive and robust actions plans to respon. ${ }^{4}$

Staff shortages in remote areas were frequently reported and the MoHP deployed a number of health workers from Kathmandu in Province seven. Such human resources shortages could be overcome in the future by mobilizing the private health facilities, health service providers and also can also mobilize retired health care providers where just the public health facilities and resources are not able to tackle of this crisis. The Policy \& Planning Division of the MoHP should estimate the required number of healthcare providers in the district wise or province wise, prepare a roster and mobilize those healthcare providers who are willing to serve in this crisis.

\section{Financing health care services}

The coronavirus outbreak was not only a threat to health but also to the economy, therefore the Federal Government of Nepal has used the regular health sector and emergency funds for COVID-19. The Federal Government has set up the COVID-19 fund and all seven provincial governments and few local level governments have also set up COVID-19 funds. The Government of Nepal has prioritized health sector and COVID response budget in the fiscal year 2020/21 which include activities to cover regular priority public health programmes, COVID-19 response, strengthening of health infrastructures and institutions to respond to infectious diseases. The budget of the MoHP has increased for health system strengthening and expanding the COVID-19 tests in all provinces to prevent the further spread of the coronavirus. The current fiscal year budget allocated provisions to establish a total of eight infectious hospitals after the COVID-19 pandemic where one 300-bedded hospital in Kathmandu valley, 50-beds infectious disease hospitals in the capital of all seven provinces of Nepal and also budget for the expansion of 250 bedded intensive care unit. However, several local governments had repeatedly criticizing the provincial and federal governments about the fund disbursements that should be timely for the uninterrupted supply of the services i.e. management of quarantine and mobilization of local and temporary staff. In the current federal context of Nepal, financing at three levels government would be a challenge for the country in the absence of an adequate health financing strategy. Budget and authority allocation could have been done well in advance for preparation to the local government, but it took time to understand its devastating effects. ${ }^{32}$

\section{Leadership and governance}

A strong leadership at all levels of society is crucial to respond to the current COVID-19 pandemic. The high-level coordination committee on the prevention and control of COVID-19 has been established and under the leadership of the MoHP has taken various steps to prevent the outbreaks. Monitoring teams and health desks have been established at major checkpoints in airport and boarder of the cities. Despite of number of GoN initiatives, there were very few well-functioning collaborations with close collaborations across the three tires of government. It has been particularly challenging to maintain interest and engage non health sectors in COVID-19 management. System responses not functioning well including logistic management, purchasing a quality of treatment commodities, managing the quarantine with having basic requirements, timely deliver the test reports and mobilizing the health facilities for COVID to non-COVID patients. ${ }^{4} 1633$ The role of provincial and local governments are also highly criticized. Different tires of government did not function well in their responses and distribution of relief, which was highly inconsistent and created conflicts among beneficiaries over the types and quantities of relief materials distributed. ${ }^{6}$

Likewise, the Disaster Management Committees at the district level also play a very minimal role and they are now not directly accountable to either provincial or local governments. Due to COVID-19 pandemic, the general health care system of Nepal has also been disrupted. People were unable to access general health services, for example women were forced to give birth at home that resulted the increase of maternal mortality vastly. ${ }^{9}$ The MoHP governance should not neglect the general health care system in the name of combating the COVID pandemic and it is necessary not only to take 
prevention and response measures, but also to have targeted public health emergency governance. It has largely to be in the area of strengthening the federal in the health system of Nepal and needs to collectively make strong emergency responses in all three tiers of government to combat the COVID-19 pandemic.

\section{Lessons learned for moving forward}

Nepal has taken numerous steps including lockdown to prevent the spread of infection, regular dissemination of the information and updated and endorsed protocols, policies, and strategies to fight against COVID-19. The WHO Building Blocks framework falls short of what is needed to fight against COVID-19 and effective prevention and response of crisis in the current Nepalese health systems. Uninterrupted supply of an essential commodities, test kits, PPEs and other medicines should be available at all health facilities and stockpiling of those commodities in advance for use during an emergency is an important lesson learned from the current response of Nepal. The incidence rate of COVID cases is being daily increasing and there is an inadequate testing at the community level so the tracing and testing capacities should be improved across the provinces for the timely response to the pandemic. Many guidelines and protocols were prepared by MoHP which is good thing but most of them were unclear and created confusions for an effective implementation at the provincial and local level governments. Many concerns raised on adhering to the guidelines and protocols at the community level such as quarantine management, general and specific health check-ups of other health problems patients, distribution of relief packages and its quality. These guidelines, standards and protocols should be updated and revised timely and adhere it at the implementation level. It shows that many provinces and local levels did not develop their response and contingency plan timely, which meant many responses this time were made at an ad hoc basis.

The surveillance system, particularly trace, test and treat, needs to be strengthened and local and provincial governments need to work closely together. Quarantine centres should have the basic facilities with having social distancing between all persons, safe and having medical service including the psychosocial support to all quarantined persons. Private providers including retired health care providers also need to be mobilized to serve patients in the needy area. Moreover, health workers should be reallocated from the less affected areas to highly affected areas for the timely trace and treat of cases. Health workers should be trained on contemporary COVID-19 and precautionary measures in the fight against the pandemic. All the health facilities should have regular services to all types of patient and ambulance services that should be monitored by the local and provincial governments to ensure the continuations and the quality of services. The current district health offices' role in COVID management shows their minimum involvement prior to federalization, although having the district health office chief as a member of the district disaster management committee needs to be strengthened to improve effective planning and management.

\section{REFERENCES}

1. WHO. Coronavirus disease (COVID-19): situation report - 171. Kathmandu: World Health Organization, 2020.

2. WHO. Monitoring the building blocks of health systems: a handbook of indicators and their measurement strategies. Geneva: World Health Organization 2010.

3. Vaidya A, Simkhada B, Simkhada P. The impact of federalization on health sector in Nepal: new opportunities and challenges. Journal of Nepal Health Research Council 2020;17(4):558-59. doi: https://doi.org/10.33314/jnhrc.v17i4.2217.

4. MoHP. Health sector emergency response plan COVID-19 pandamic. July ed. Kathmandu: Ministry of Health and Population, 2020.

5. Anmol A, Poudel S. Family of man suspected of COVID-19 infection refuses to accept his body alleging hospital of negligence. The Kathmandu Post (April 4, 2020) 2020.

6. Gautam D. Nepal's readiness and response to COVID-19: Key initiatives, emerging challenges and the way forward. NDRC Nepal 2020(2):117.

7. Shrestha R, Shrestha $S$, Khanal $P$, et al. Nepal's first case of COVID-19 and public health response. Journal of Travel Medicine 2020;27(3):taaa024. doi: 10.1093/jtm/taaa024.

8. MoHP. Nepal health sector strategy 2016-2021. Kathmandu: Ministry of Health and Population, 2016. 
9. Poudel A. A 200 percent increase in maternal mortality since the lockdown began. The Kathmandu Post (May 27, 2020) 2020.

10. Chalise $H$, Dhungana $H$. Fears of COVID-19 catastrophe as Nepal reports death from new Coronavirus. J Phys Med Rehabil Disabil 2020;6:047.

11. Basnet L. Errors of testing casused death of youth. Annapurna Post (June 5, 2020) 2020 2020.

12. Tamang $P$, Mahato $P$, Shahi $P$, et al. COVID-19 quarantine: a key part of prevention in Nepal. Journal of Karnali Academy of Health Sciences 2020;3 doi: 10.3126/jkahs.v3i0.29432.

13. Wilder-Smith A, Freedman DO. Isolation, quarantine, social distancing and community containment: pivotal role for old-style public health measures in the novel coronavirus (2019-nCoV) outbreak. Journal of Travel Medicine 2020;27(2):taaa020. doi: https://doi. org/10.1093/jtm/taaa020.

14. MoHP. Standard operating procedure on repatriation and quarantine COVID-19: reference document. Kathmandu: Ministry of Health and Population, 2020.

15. MoHA. Disaster risk reduction national strategic plan of action 2018-2030. Kathmandu: The Government of Nepal Ministry of Home Affairs, 2018.

16. Bhattarai $S$, Dhungana J, Ensor $T$, et al. Assessment of service availability and infection prevention measures in hospitals of Nepal during the transition phase of COVID-19 case surge. Medrxiv 2020 doi: 10.1101/2020.05.13.20097675.

17. Paudel M. Quarantine facilities in province 5 crowded and mismanaged. The Kathmandu Post (May 19, 2020) 2020.

18. Torales J, O'Higgins M, Castaldelli-Maia JM, et al. The outbreak of COVID-19 coronavirus and its impact on global mental health. International Journal of Social Psychiatry 2020:0020764020915212.

19. UN-Women. Violence against women and girls: The shadow pandemic: The UN Women, 2020.

20. 20. The Kathmandu Post. Calls to national helpline for women are growing, but it is accessible to only a few. The Kathmandu Post (April 2, 2019) 2020.

21. MoHP. National health policy 2076 Kathmandu: Ministry of Health and Population 2019.
22. Livingston $E$, Desai A, Berkwits $M$. Sourcing personal protective equipment during the COVID-19 pandemic. JAMA 2020;323(19):191214. doi: 10.1001/jama.2020.5317.

23. Sapkota R. Protecting those who protect us from the epidemic. Nepali Times (March 25, 2020) 2020.

24. Wagle A. Covid-19 exposes a governance crisis. The Kathmandu Post (April 13, 2020) 2020.

25. Aryal N. Stop chemical spray in human body. Swasthya Khabar Patrika (April 28, 2020) 2020.

26. Larson HJ. The biggest pandemic risk? Viral misinformation. Nature 2018;562(7726):30910. doi: https://doi.org/10.1038/d41586-01807034-4.

27. Wilson ME, Chen LH. Travellers give wings to novel coronavirus (2019-nCoV). Journal of Travel Medicine 2020;27(2):taaa015. doi: https://doi.org/10.1093/jtm/taaa015.

28. Bhattarai A, Karki B. Covid-19 pandemic and mental health issues. J Lumbini Med Coll 2020;8(1) doi: https://doi.org/10.22502/jlmc. v8i1.383.

29. Ojha A. Husband of newborn mother who died of COVID-19 says they had to wait for seven hours to get an ambulance. The Kathmandu Post (May 19, 2020) 2020.

30. Sijapati A. With $2^{\text {nd }}$ COVID-19 fatality, Nepal issues funeral guideline. Nepali Times (May 20, 2020) 2020.

31. The Rising Nepal. Disposes dead body of COVID-19 infected person in jungle. The Rising Nepal (May 22, 2020) 2020.

32. Koirala J, Acharya S, Neupane $M$, et al. Government preparedness and response for 2020 pandemic disaster in Nepal: a case study of COVID-19. Management 2020 doi: 10.33774/ coe-2020-ghj8v.

33. Sapkota R. Why Nepal lags in COVID-19 testing Kathmandu: Nepali Times (June 21, 2020); 2020 [Available from: https://www.nepalitimes.com/ latest/why-nepal-lags-in-covid-19-testing/ accessed July 2020. 